Bull. Chem. Soc. Ethiop. 2021, 35(3), 587-600.

(C) 2021 Chemical Society of Ethiopia and The Authors

ISSN 1011-3924

DOI: https://dx.doi.org/10.4314/bcse.v35i3.10

Printed in Ethiopia

Online ISSN 1726-801X

\title{
THEORETICAL AND EXPERIMENTAL INVESTIGATION OF THIOUREA DERIVATIVES: SYNTHESIS, CRYSTAL STRUCTURE, IN-SILICO AND IN-VITRO BIOLOGICAL EVALUATION
}

\author{
Muhammad Asam Raza ${ }^{1 *}$, Amina Sharif ${ }^{1}$, Muhammad Danish ${ }^{1}$, Shafiq Ur Rehman ${ }^{2}$, Armand \\ Budzianowski ${ }^{3}$ and Jan K. Maurin ${ }^{3,4}$ \\ ${ }^{1}$ Department of Chemistry, Hafiz Hayat Campus, University of Gujrat, Gujrat, Pakistan \\ ${ }^{2}$ Department of Chemistry, University of Central Punjab, Lahore Campus, Lahore, Pakistan \\ ${ }^{3}$ National Medicines Institute, Chełmska 30/34, 00-725 Warsaw, Poland \\ ${ }^{4}$ National Centre for Nuclear Research, Andrzeja Sołtana 7, 05-400 Otwock, Poland
}

(Received August 8, 2021; Revised December 22, 2021; Accepted December 26, 2021)

\begin{abstract}
In this study, five different thiourea derivatives were synthesized from aryl amines according to the reported method. 1-Benzoyl-3-(4-methoxyphenyl)thiourea (2) was confirmed with single crystal XRD analysis while 1-benzoyl-3-phenylthiourea (1), 1-benzoyl-3-(4-hydroxyphenyl)thiourea (3), 1-benzoyl-3-(2-nitrophenyl) thiourea (4) and 1-benzoyl-3-p-tolylthiourea (5) were elucidated with FTIR and NMR techniques. The geometry optimization of the targeted molecules was accomplished with density functional theory applying B3LYP function. The experimental (XRD) and calculated (DFT) bond angles and bond lengths were compared. The frontier molecular orbitals and molecular electrostatic potential were computed to determine the charge density distribution and possible sites for electrophilic and nucleophilic reactions of the crystalline compound. The synthesized compounds were evaluated as an anti-radical scavenger and enzyme (esterases and protease) inhibitor using in-vitro models. The results confirmed that the synthesized molecules have good anti-oxidant property while a moderate enzyme inhibiting activity. Docking study was conducted with acetylcholine and butyrylcholine esterase which suggested that molecules under study have a potential to inhibit these esterases and protease enzymes. On the basis of in-vitro studies, it is concluded that compound $\mathbf{2}$ is most active against all tested assays.
\end{abstract}

KEY WORDS: Thiourea, 2,2-Diphenyl-1-picrylhydrazyl, Enzyme inhibition, Density functional theory, Docking studies

\section{INTRODUCTION}

Synthesis of small structurally diverse molecules which can bind macromolecules can serve as the starting points for the synthesis of drugs/probes. Organic chemists can be synthesized moieties fit for pharmaceutical formulations [1]. Using the innovative knowledge of biological targets through various softwares, drugs are being designed. The smaller organic molecules interact with proteins by either inhibiting it or activating it and in consequence organism benefits therapeutically. In short, drug is designed to be corresponding in structure and charge to biomolecular targets [2]. Therapeutic uses of synthetic compounds are widespread, and being used as anti-HIV, antibacterial, antimycobacterial, antifungal, antileishmanial, antimalarial, anticonvulsant, antidepressant and anticancer agents [3-8]. The eye catching aspect of synthetic chemistry is to change the chemical and physical properties of the nitrogen containing molecule by just changing substitutions on nitrogen atom. Compounds containing heteroatoms, being important in biological as well as for industrial and such compounds are considered as one of the largest parts of organic chemistry. Among heteroatoms, sulfur and nitrogen containing compounds are of special interest for the researchers [9]. Thiourea is a versatile group of organic reagents possessing considerable range of applications. They possess functional organic moiety which is similar to the urea with exception of the replacement of the $\mathrm{O}$ atom with the $\mathrm{S}$. Difference in properties of these compounds is due to the electronegativity difference between oxygen and

*Corresponding author. E-mail: asamgcu@yahoo.com

This work is licensed under the Creative Commons Attribution 4.0 International License 
sulfur atoms [8]. A wide range of biological activities exhibited by thiourea include herbicidal, anti-fungal, anti-bacterial, insecticidal and plant growth regulating properties [10].

Enzymes present in all living organisms and specific in their actions in sense of biochemical reactions occurring in plants, animals, microorganisms and human beings. Catalytic capabilities of enzymes make them unique. In development of pharmaceutical research, application of enzyme technologies is considered as the growing field [11]. Enzymes are biomolecules which, due to their greater affinity and specificity, bind to their substrates specifically. The substances which decrease the rate of an enzyme are known as inhibitors. Some of them act directly on enzymes and some combine with a substrate or cofactor. These inhibitors attached or interact to the different amino acids located on the active site of the enzyme through van der Waals forces, $\pi-\pi$ interactions and hydrogen bonding, etc [12]. In our body many free radical are continuously generated through different mechanism, which may lead to damage biomolecules. It is necessary to stop these radicals and to protect our body by capturing them. Keeping in view the importance of the enzyme and free radicals, the present study was designed to synthesize the substituted thiourea derivatives, optimization of their structures and biological evaluation as antioxidant and enzyme inhibition.

\section{EXPERIMENTAL}

\section{Materials}

All chemical and solvents used in the synthesis along biological evaluation of the targeted compound were purchased from Sigma Aldrich.

\section{Synthesis of thiourea derivatives (1-5)}

The targeted compounds were prepared in accordance to the literature method [13]. Potassium thiocyanate $(0.02 \mathrm{~mol})$ was dissolved in dry acetone $(20 \mathrm{~mL})$ on continuously stirring followed by the drop wise addition of benzoyl chloride $(0.02 \mathrm{~mol})$. Then the mixture was stirred for $20 \mathrm{~min}$. A solution of aryl amine $(0.02 \mathrm{~mol})$ in acetone was then added and the reaction mixture was stirred for almost $10 \mathrm{~min}$ followed by refluxing for 2 hours (Scheme 1). The progress of reaction was monitored on TLC and on reaction completion, chilled distilled water was added to the mixture. The precipitates formed were filtered, washed several times with the water and then dried in an oven.

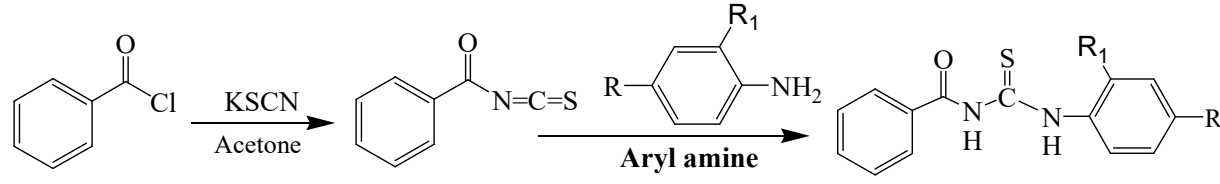

Benzoyl Chloride Isithiocyanate

Thiourea

1: $\mathrm{R}=\mathrm{H}, \mathrm{R}_{1}=\mathrm{H} ; \mathbf{2}: \mathrm{R}=-\mathrm{OCH}_{3}, \mathrm{R}_{1}=\mathrm{H} ; \mathbf{3}: \mathrm{R}=-\mathrm{OH}, \mathrm{R}_{1}=\mathrm{H} ; \mathbf{4}: \mathrm{R}=\mathrm{H}, \mathrm{R}_{1}=-\mathrm{NO}_{2} ; \mathbf{5} ; \mathrm{R}=\mathrm{CH}_{3}$, $\mathrm{R}_{1}=\mathrm{H}$

Scheme 1. Synthetic scheme of thiourea derivatives.

\section{Antioxidant activity}

The ability of synthesized molecules (1-5) to scavenge free radical was evaluated by following the method of Shahwar et al. [14]. $100 \mu \mathrm{L}$ of synthesized compound (5 $\mathrm{mg} / \mathrm{mL}$ in DMSO) was added to $2 \mathrm{~mL}$ of the DPPH solution (methanol). Incubation of reaction mixture was done for 30 
min at room temperature. Reduction of the absorbance after incubation was recorded at $517 \mathrm{~nm}$. Determination of the percentage scavenging ability of synthetic compound was evaluated using following formula;

$$
\text { Inhibition of DPPH }(\%)=\frac{\mathrm{A}-\mathrm{B}}{\mathrm{A}} X 100
$$

where $\mathrm{A}$ is the Absorbance of blank and $\mathrm{B}$ is the absorbance of sample.

\section{Protease inhibition assay}

The activity of protease inhibition was performed in accordance to the method of Jedinak et al. with minor modification [15]. The $0.3 \mathrm{~mL}$ of the enzyme and inhibitor $(100 \mu \mathrm{L})$ was mixed and incubated at $37^{\circ} \mathrm{C}$ for $15 \mathrm{~min}$ after that $0.6 \mathrm{mM}$ of the substrate solution was added followed by adding $2.5 \mathrm{~mL}$ of a tris buffer. Incubation of the mixture was done at $37^{\circ} \mathrm{C}$ for $30 \mathrm{~min}$ after which the reaction was stop by adding $50 \mu \mathrm{L}$ of $\mathrm{NaOH}(0.1 \mathrm{M})$. The absorbance was measured at 410 $\mathrm{nm}$ and inhibition (\%) was calculated;

$$
\% \text { Inhibition }=\frac{\text { Absorbance }(\text { blank })-\text { Absorbance }(\text { test })}{\text { Absorbance }(\text { blank })} \times 100
$$

Acetyl/butyrylcholine esterase assay

Following the in-vitro method of Shahwar et al. [14] acetyl/butyryl choline esterase inhibitory potential was measured [16]. Reaction mixture contained $100 \mu \mathrm{L}$ DTNB, $0.5 \mathrm{~mL}$ of the $100 \mathrm{mM}$ tris buffer of $\mathrm{pH} 7.8,100 \mu \mathrm{L}$ of the sample under consideration and $100 \mu \mathrm{L}$ of enzyme. The mixtures were incubated at the $37^{\circ} \mathrm{C}$ for $15 \mathrm{~min}$. Initiation of the reaction was started after the addition of respective substrate (acetyl/butyryl thiocholine iodide). Hydrolysis of the substrate was then monitored at $412 \mathrm{~nm}$ after $30 \mathrm{~min}$. Calculation of \% inhibition was done by the following formula:

Inhibition $(\%)=\frac{E-S}{E} \times 100$

where $\mathrm{E}$ is the activity of the enzyme in the blank and $\mathrm{S}$ is the activity of enzyme with the tested compound.

\section{Density functional theory}

DFT calculations were carried out using Gaussian 09 while results were visualized with Gauss View 5.0. The structures of the targeted compounds (derivative of thiourea) were optimized using DFT method and the B3LYP hybrid functional. All calculations were carried out with $6-31 G(d, p)$ basis set $[17,18]$. During optimization with DFT, the input file was taken from the XRD data of synthesized compound (where applicable) and matched with the experimental data via DFT studies $[19,20]$.

Docking studies

Docking study was carried out with Molecular Operating Environment (MOE) [19, 21]. Crystal structures of $\mathrm{AChE}$ and $\mathrm{BChE}$ with $\mathrm{PDB}$ codes 1EVE and 1P0I, respectively, were selected for docking studies. The three-dimensional (3D) structure of the synthesized compound was drawn through the builder program implemented in MOE. The geometrical parameters for 3D structure of the synthesized compound was optimized, and partial charges were calculated before docking. 
For 1EVE, the active site of the prepared enzyme was defined as a residue within $10 \AA$ of the reference ligand (donepezil). Trp84 and Trp82 key tryptophan residues in AChE and BChE respectively are conserved. The lowest energy minimized pose among 30 was used for further analysis. Views of docking pose and analysis of their surface with graphical representations were done using MOE and Discovery Studio Visualizer.

\section{RESULTS AND DISCUSSION}

\section{Chemistry}

Synthetic chemistry is continuously helping human beings for synthesizing novel and potent molecules for better health and curing various diseases. In this study, thiourea derivatives were synthesized from cheaper reactants according to the already well-established method. The monitoring of reaction progress was checked on TLC and after completion of reaction, the products were washed and dried. The structures of the synthesized compounds except 2 were determined on the basis of FTIR and NMR spectral techniques while for 2, single crystal XRD analysis was done to determine the exact structure of the molecule (2). In FTIR the disappearance of band $\left(3300 \mathrm{~cm}^{-1}\right)$ of $\mathrm{NH}_{2}$ group and appearance of new peak at about $3100 \mathrm{~cm}^{-1}$ give the indication about the formation of the products. The FTIR bands near $3000 \mathrm{~cm}^{-1}, 1600 \mathrm{~cm}^{-1}, 1300$ $\mathrm{cm}^{-1}$ and $1200 \mathrm{~cm}^{-1}$ correspond to $\mathrm{C}-\mathrm{H}, \mathrm{C}=\mathrm{O}, \mathrm{C}-\mathrm{N}$ and $\mathrm{C}=\mathrm{S}$, respectively [22]. The NMR technique also supported the synthesis of the compounds as both aromatic systems showed multiplicity in the ${ }^{1} \mathrm{H}$ NMR while in the products where substitution on the aryl amine showed two different types of signals as mentioned in the NMR data.

1-Benzoyl-3-phenylthiourea (1). Yield: 81\%; IR (KBr, cm $\left.{ }^{-1}\right) v_{\max }: 3107(\mathrm{NH}), 3031(\mathrm{CH}), 1610$ $(\mathrm{C}=\mathrm{O}), 1238(\mathrm{C}=\mathrm{S}) ;{ }^{1} \mathrm{H}$ NMR $(300 \mathrm{MHz}$, chloroform- $d) \delta$ 7.70-7.62 (m, 5H), 7.35-7.14 $(\mathrm{m}, 5 \mathrm{H})$, ${ }^{13} \mathrm{C}$ NMR (100 MHz, DMSO-d6) $\delta 171.07,163.86,134.16,131.62,130.09,124.83,123.31$, $121.12,120.82,119.20$.

1-Benzoyl-3-(4-hydroxyphenyl)thiourea (3). Yield: 73\%; IR (KBr, $\left.\mathrm{cm}^{-1}\right) v_{\max }$ : $3120(\mathrm{NH}), 3045$ $(\mathrm{CH}), 1595(\mathrm{C}=\mathrm{O}), 1225(\mathrm{C}=\mathrm{S}) ;{ }^{1} \mathrm{H}$ NMR $(300 \mathrm{MHz}$, chloroform- $d) \delta 7.76-7.52(\mathrm{~m}, 5 \mathrm{H}), 7.35$ $7.29(\mathrm{~m}, 2 \mathrm{H}), 6.74-6.61(\mathrm{~m}, 2 \mathrm{H}) .{ }^{13} \mathrm{C}$ NMR $(100 \mathrm{MHz}, \mathrm{DMSO}-\mathrm{d} 6) \delta 168.86,161.86,150.19$, $131.62,127.38,126.09,121.83,120.12,117.36,111.35$.

1-Benzoyl-3-(2-nitrophenyl)thiourea (4). Yield: 59\%; IR (KBr, $\left.\mathrm{cm}^{-1}\right) v_{\max }: 3091(\mathrm{NH}), 3004(\mathrm{CH})$, $1617(\mathrm{C}=\mathrm{O}), 1234(\mathrm{C}=\mathrm{S}) ;{ }^{1} \mathrm{H} \mathrm{NMR}(300 \mathrm{MHz}$, chloroform- $d$ ) $\delta 8.18(\mathrm{dd}, J=8.6,1.1 \mathrm{~Hz}, 1 \mathrm{H})$, $7.82-7.76(\mathrm{~m}, 2 \mathrm{H}), 7.67-7.61(\mathrm{~m}, 3 \mathrm{H}), 7.54-7.44(\mathrm{~m}, 2 \mathrm{H}), 6.94(\mathrm{~m}, 1 \mathrm{H}) .{ }^{13} \mathrm{C}$ NMR $(100 \mathrm{MHz}$, DMSO-d6) $\delta 172.04,164.31,133.27,132.17,130.02,129.28,128.01,124.13,122.12,120.47$, $119.41,116.11$.

1-Benzoyl-3-p-tolylthiourea (5). Yield: 79\%; IR (KBr, cm $\left.{ }^{-1}\right) v_{\max }: 3109(\mathrm{NH}), 2985(\mathrm{CH}), 1621$ $(\mathrm{C}=\mathrm{O}), 1204(\mathrm{C}=\mathrm{S}) ;{ }^{1} \mathrm{H}$ NMR $(500 \mathrm{MHz}$, Chloroform- $d$ ) $\delta$ 7.80-7.62 (m, 5H), 7.50-7.34 (m, 4H), $2.28(\mathrm{~s}, 1 \mathrm{H}) .{ }^{13} \mathrm{C}$ NMR $(125 \mathrm{MHz}$, DMSO-d6) $\delta 174.47,163.86,135.29,131.62,130.03,129.51$, $126.09,127.47,124.52,120.07,26.23$.

\section{X-Ray diffraction studies of compound 2}

For X-ray diffraction studies, colorless crystals having dimensions $0.56 \times 0.33 \times 0.18 \mathrm{~mm}$ were applied. The crystal was placed on an Xcalibur $\mathrm{R}$ Oxford Diffraction $\kappa$ axis four-circle diffractometer equipped with a Ruby CCD detector. After initial diffraction experiment the 
triclinic P-1 unit cell of dimensions ca. $\mathrm{a}=5.44 \AA, \mathrm{b}=9.84 \AA, \mathrm{c}=13.49 \AA, \alpha=91.5^{\circ}, \beta=93.5^{\circ}$ and $\gamma=93.7^{\circ}$ was established. 22839 reflections were measured consecutively ( 2769 unique). After initial corrections for Lorenz-polarization effects the data were used for structure solution. All non-hydrogen atoms were localized from the initial E maps. After isotropic and consecutive anisotropic refinement using SHELXL-97 program the hydrogen atoms could be localized [23]. After completion of the molecular model the diffraction data was corrected for absorption. Final refinement of the structure comprised positional and anisotropic displacement parameters for the non-hydrogen atoms. All hydrogen atoms not involved in hydrogen bonds were included into the model applying standard geometrical criteria and isotropic displacement parameters calculated from the respective equivalent isotropic values for the heavy atoms they are bonded. The positional parameters of hydrogen atoms bonded to nitrogen were refined freely. Final experimental and structural parameters are shown in Table 1. Crystal structure of 1-benzoyl-3-(4methoxyphenyl)thiourea is dominated by hydrogen-bonded dimers shown in Figure 1. Strong $\mathrm{N}-\mathrm{H} \cdots \mathrm{S}$ intermolecular hydrogen bonds between centro-symmetrically related molecules and $\mathrm{N}-\mathrm{H} \cdots \mathrm{O}$ intra-molecular bonds are shown as the dashed lines.

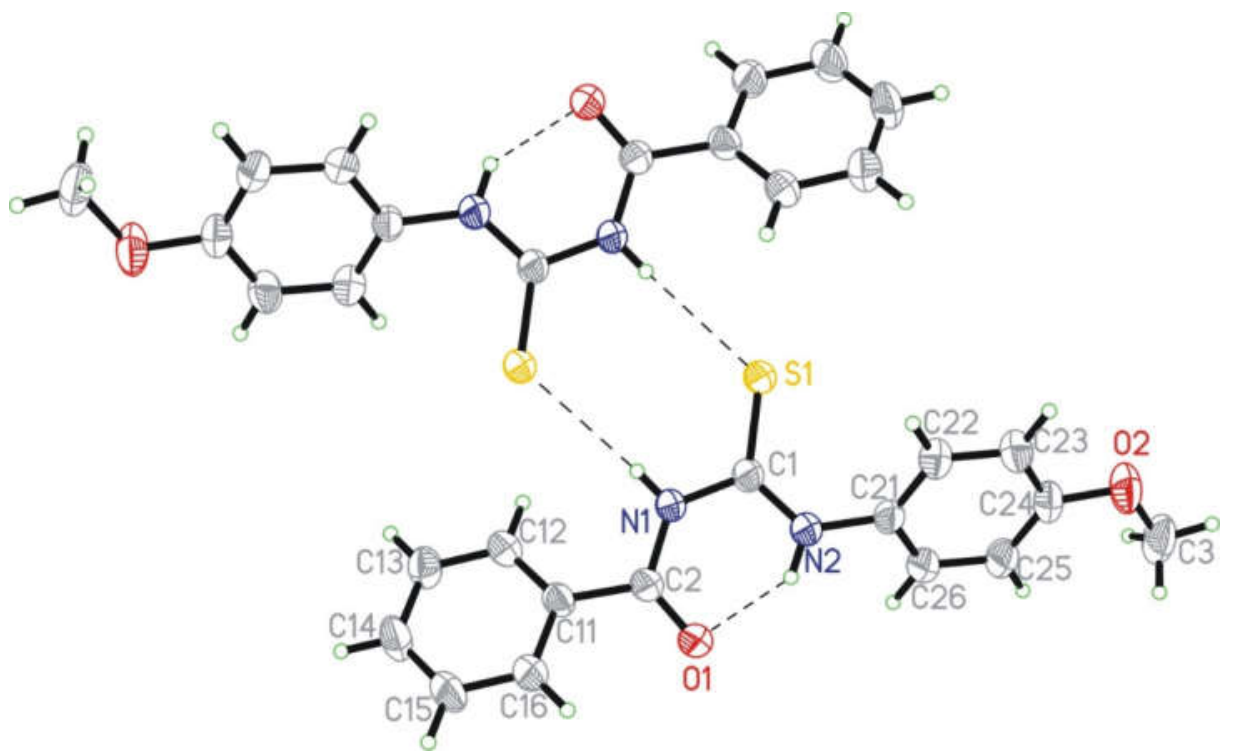

Figure 1. Crystal unit of the synthesized compound (2).

Molecular geometry and DFT studies

Before proceeding in physical properties calculation, it is necessary to perform the geometry optimization of the studied molecules (Figure 2). The equilibrium geometry of the molecule in gaseous phase was fully optimized at the DFT level using B3LYP functional together with the standard 6-31G(d,p) basis set. Figure 3, shows shapes of the highest occupied and lowest unoccupied molecular orbital (HOMO and the LUMO) for the studied compounds, drawn by Gaussian View 5.0 using B3LYP/6-31G(d,p) method. The energy gap between HOMO and LUMO of compound $\mathbf{1}, \mathbf{2}, \mathbf{3}, \mathbf{4}$ and $\mathbf{5}$ is $5.07,4.66,4.74,4.23$ and $4.88 \mathrm{eV}$, respectively as shown in Figure 3. 
Table 1. Experimental and structural parameters of $\mathbf{2}$.

\begin{tabular}{|c|c|}
\hline Empirical formula & $\mathrm{C}_{15} \mathrm{H}_{14} \mathrm{~N}_{2} \mathrm{O}_{2} \mathrm{~S}$ \\
\hline Formula weight & 286.34 \\
\hline Temperature/K & $293(2)$ \\
\hline Crystal system & triclinic \\
\hline Space group & $P-1$ \\
\hline$a / \AA$ & $5.4450(2)$ \\
\hline$b / \AA$ & $9.8344(3)$ \\
\hline$c / \AA ̊$ & $13.4873(4)$ \\
\hline$\alpha /^{\circ}$ & $91.523(2)$ \\
\hline$\beta /{ }^{\circ}$ & $93.559(2)$ \\
\hline$\gamma /{ }^{\circ}$ & $93.671(2)$ \\
\hline Volume $/ \AA^{3}$ & $719.01(4)$ \\
\hline$Z$ & 2 \\
\hline$\rho_{\text {calc }} \mathrm{g} / \mathrm{cm}^{3}$ & 1.323 \\
\hline$\mu / \mathrm{mm}^{-1}$ & 2.025 \\
\hline $\mathrm{F}(000)$ & 300.0 \\
\hline Crystal size $/ \mathrm{mm}^{3}$ & $0.564 \times 0.329 \times 0.185$ \\
\hline Radiation & $\mathrm{Cu} \mathrm{K} \alpha(\lambda=1.54184)$ \\
\hline $2 \Theta$ range for data collection $/{ }^{\circ}$ & 6.56 to 142.54 \\
\hline Index ranges & $-6 \leq \mathrm{h} \leq 6,-12 \leq \mathrm{k} \leq 12,-16 \leq 1 \leq 16$ \\
\hline Reflections collected & 22839 \\
\hline Independent reflections & $2769\left[R_{\text {int }}=0.0329, R_{\text {sigma }}=0.0153\right]$ \\
\hline Data/restraints/parameters & $2769 / 0 / 188$ \\
\hline Goodness-of-fit on $\mathrm{F}^{2}$ & 1.023 \\
\hline Final $R$ indexes $[\mathrm{I}>=2 \sigma(\mathrm{I})]$ & $R_{l}=0.0363, \mathrm{wR}_{2}=0.1023$ \\
\hline Final $R$ indexes [all data] & $R_{I}=0.0453, \mathrm{wR}_{2}=0.1110$ \\
\hline Largest diff. peak/hole / e $\AA^{-3}$ & $0.16 /-0.20$ \\
\hline
\end{tabular}

Table 2 presents results of the ground state total energy and electronic states HOMO and LUMO of the crystalline molecule (2). The energy of HOMO is often associated with the electron donating ability of molecules, whereas the energy of LUMO is associated with the electron accepting ability of molecules. Therefore, high value of HOMO indicated more tendency to donate electrons to an empty molecular orbital of appropriate acceptor (molecule) with small energy. Likewise, a low value of LUMO indicated high tendency to accept electrons from donor $[24,25]$.

Table 2. Different parameters calculated from DFT of compound (2).

\begin{tabular}{|l|l|l|l|}
\hline Energy (hartree) & -1237.9460 & Enthalpy & -1237.6580 \\
\hline$\mu$ (chemical potential) & -0.1340 & $\Omega$ (Electrophilicity) & 0.1292 \\
\hline $\mathrm{y}$ (chemical hardness) & 0.0634 & IP (ionization potential) & 0.2034 \\
\hline $\mathrm{X}$ (electronegativity) & 0.1400 & EA (electron affinity) & 0.0766 \\
\hline HOMO & -0.2034 & Dipole moment & 5.0548 \\
\hline LUMO & -0.0766 & Gibbs Free Energy & -1237.7245 \\
\hline (LUMO-HOMO) & 0.1266 & Nuclear Repulsion energy & 1478.0131 \\
\hline
\end{tabular}

The results as presented in Table 2 showed that the synthesized molecule has a higher energy of HOMO. HOMO and LUMO gap between in the molecule is also vital feature for the description 
of the molecule. The Large values of the energy gap indicate high electronic stability and such molecule show less reactivity. Furthermore, low value imply that it will be easier to transfer an electron from the HOMO to LUMO, which can result in good reactivity of the compound. The results of the synthesized molecule as shown in Table 2 also has lesser energy gap. The correlation between bond angle and bond length of XRD (experimental) and DFT (theoretical) was done using MS Excel Program and it was found that $\mathrm{R}^{2}$ value for bond length and bond angle is 0.9247 and 0.9681 respectively. This gives the clear indication about the close relation between experimental and theoretical studies. B3LYP functional used in this study has a high efficiency to calculate the electronic properties of the studied molecule, such as the ionization potential, electron affinity, electronegativity, chemical hardness, chemical softness and electrophilicity. All global chemical indexes of $\mathbf{2}$ are summarized in Table 2 for studied compound.

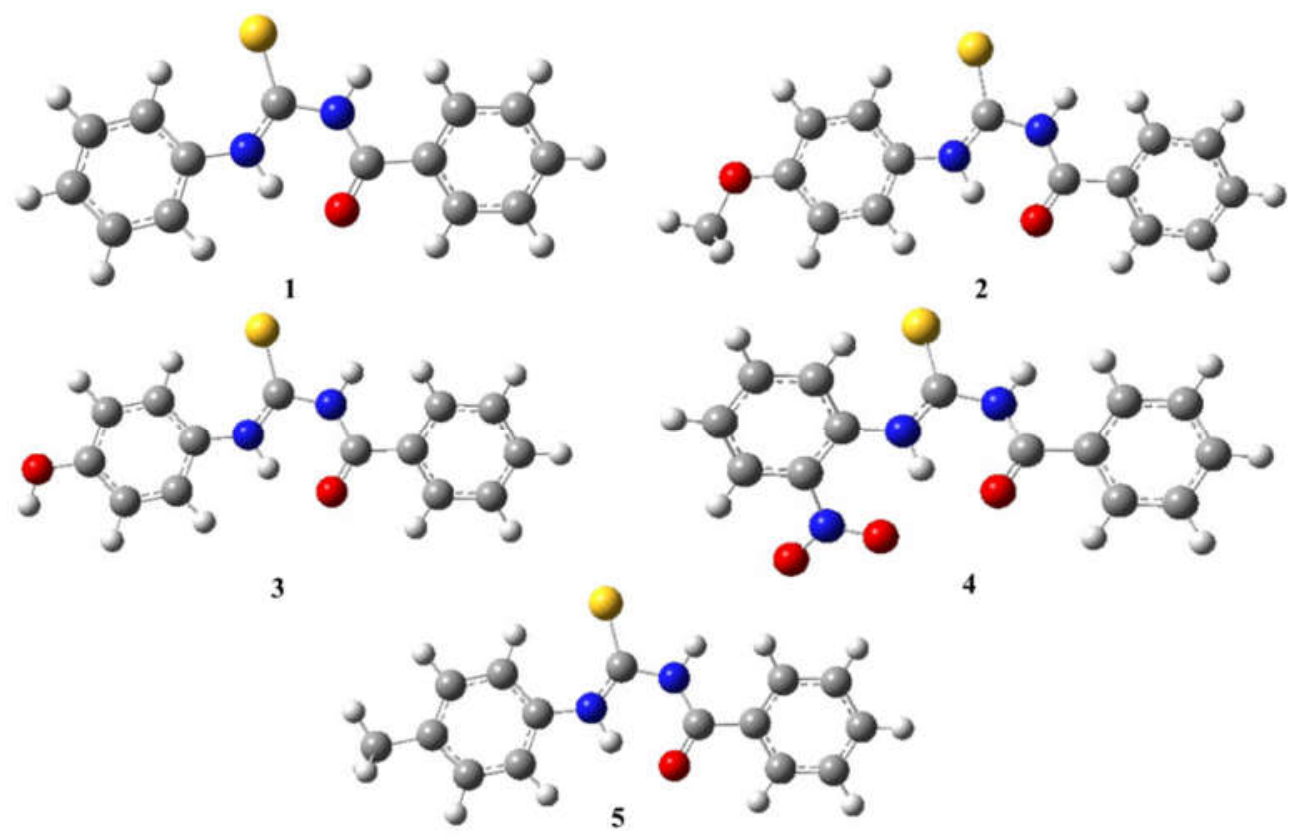

Figure 2. Optimized structure of the synthesized compounds. 

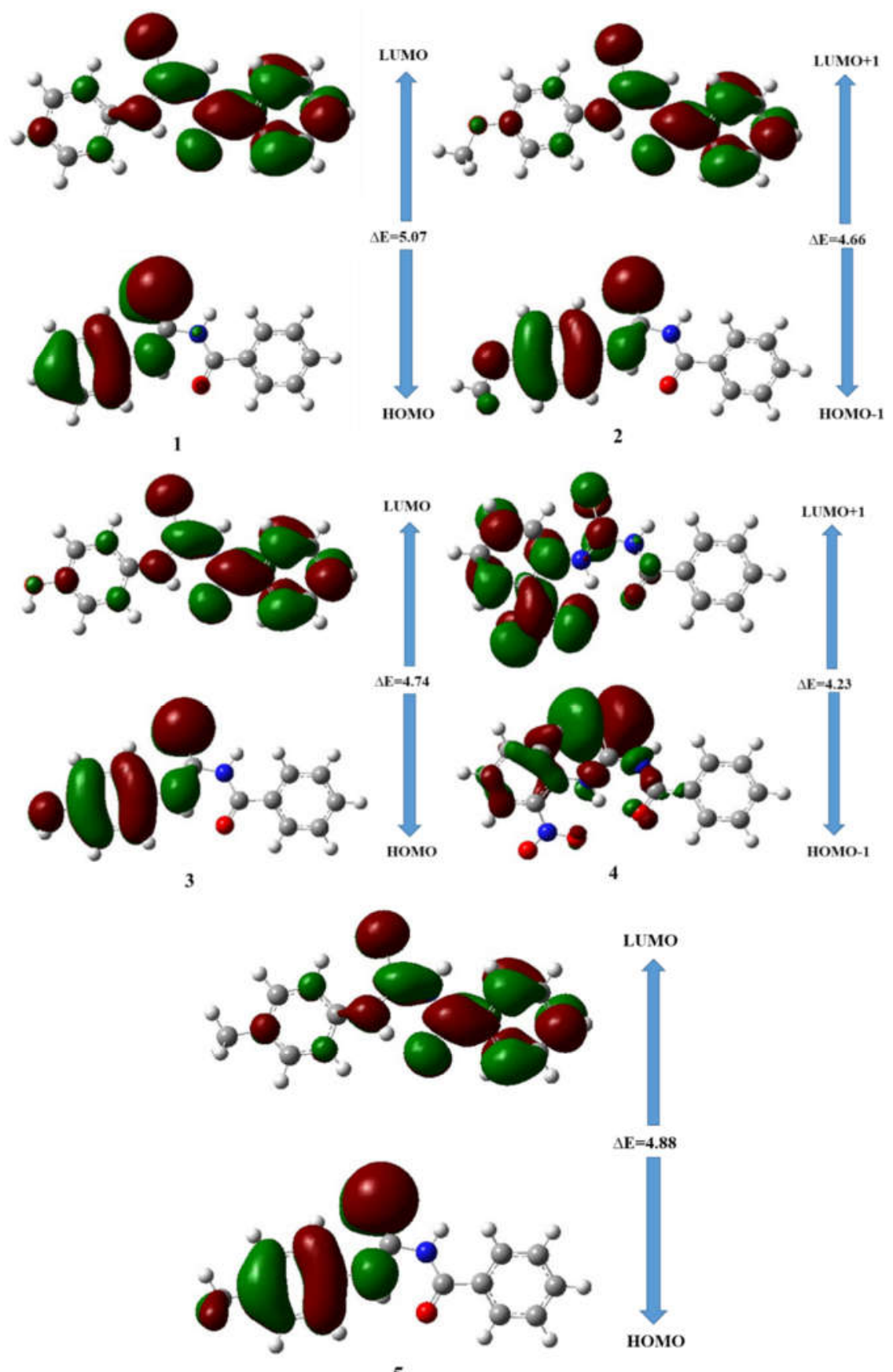

Figure 3. Energy gap between HOMO and LUMO of the synthesized compounds.

Bull. Chem. Soc. Ethiop. 2021, 35(3) 

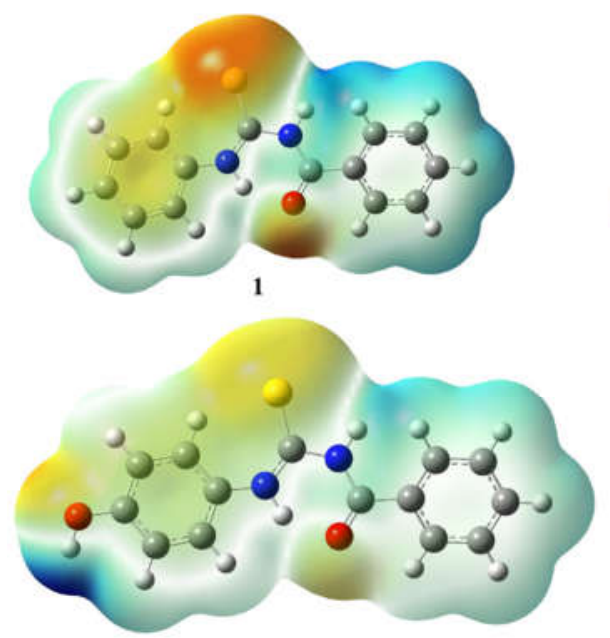

3

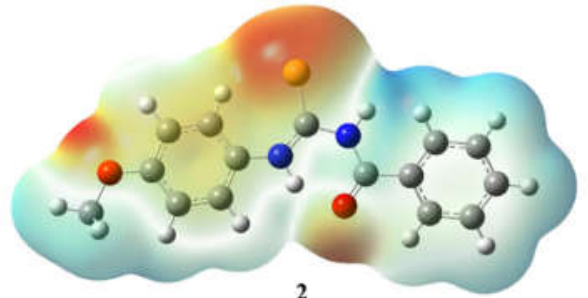

2

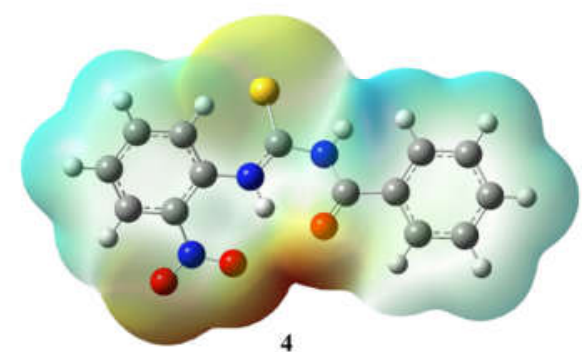

4

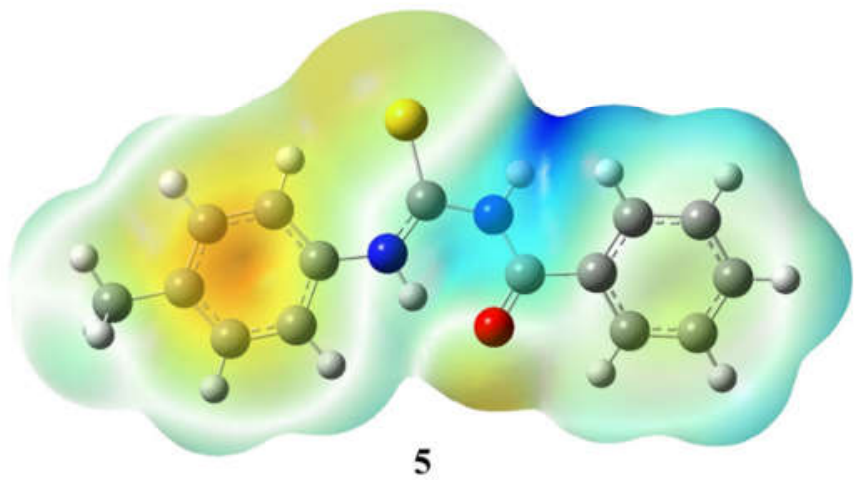

Figure 4. Molecular electrostatic potential of the synthesized compounds.

The molecular electrostatic potential (MEP) surface depict values of potential at various points in the target compound. It is used to differentiate between positive, negative and neutral charges on the molecule with different colors. The colors on the surfaces follow the order; red $>$ orange $>$ yellow $>$ green $>$ blue with respect to charge distribution [26]. The nitrogens (red) represent regions of negative potential where electrophilic attack may occur. Hydrogens (blue) of methyl and aromatic ring show positive potential and hence suitable sites for nucleophilic attack (Figure 4).

\section{Radical scavenging activity}

Antioxidants prevent the oxidation of other substances and in such reactions hydrogens or electrons are referred to possess an oxidizing potential. Many reactions in our bodies produce free radicals which destroy cells [27]. DPPH is vastly used in evaluation of free radical, scavenging capacity of different oxidants [28]. The ability of synthesized compound to reduce an oxidant was determined using 1,1-diphenyl-2-picrylhydrazyl radical, which by reduction is converted to 1,1- 
diphenyl-2-picrylhydrazine [29]. The lambda maxima of DPPH is $517 \mathrm{~nm}$ as reported in literature [30]. Antioxidants react and reduce the DPPH (stable free radical) by the formation of DPPH-H adduct and thus the absorbance of radical is being decreased. Hydrogen donating power of samples or antioxidant compounds indicates the scavenging potential as well as degree of discoloration [31]. Results showed that targeted thiourea derivatives showed good response against test assay. The maximum activity was exhibited by compound $2\left(90.5 \pm 2.1 \%\right.$ with $\mathrm{IC}_{50}$ value $45 \pm 2 \mu \mathrm{g}$ ) as shown in Table 3 . The order of all other compounds is $\mathbf{3}>\mathbf{5}>\mathbf{4}>\mathbf{1}$.

\section{Enzyme inhibition study}

For maintenance of a steady state of all organisms it is essential to control enzyme activity. Depending upon the need of cells enzyme activities are regulated either up or down. This is possible only by controlling activities of enzymes in metabolic pathways. Body's natural steady state is adversely affected by the disruption of enzymatic control. Present study comprises evaluation of enzyme inhibitory potential of the synthesized compound against three enzymes (Protease, butyrylcholine esterase and acetylcholine esterase) using in-vitro models. It is depicted from results that thiourea derivatives showed remarkable inhibition against both esterase enzymes ranged from $54.4 \pm 1.2 \%$ to $74.3 \pm 2.0 \%$. The maximum activity was shown by compound 2 while least response was depicted by $\mathbf{1}$. The order of synthesized compounds against $\mathrm{BChE}$ is $\mathbf{2}>\mathbf{4}>\mathbf{3}$ $>\mathbf{5}>\mathbf{1}$. Acetylcholine esterase (AChE), one of the most essential enzymes in the serine hydrolases family, catalyzes the hydrolysis of a neurotransmitter acetylcholine, which plays a key role in memory and cognition [32]. Acetyl cholinesterase is the terminator, enzyme for the transmission of nerve impulse at the synapses by quickly hydrolyzing acetylcholine to acetate and choline. AChE inhibition strategy is used in treatment of several diseases such as senile dementia, Parkinson and Alzheimer diseases [33]. Major therapeutic strategies involve the inhibition of biological activity of AChE in order to increase the level of acetylcholine in the brain. It concluded that synthesized compound is has good activity against AChE as well as BChE (Table 3). Hydrolysis of the peptide bonds occurs by the action of proteases which disrupt the primary structure of proteins. In higher organisms, digestion, proenzyme or prohormone activation and various defense mechanisms occur by the activity of the proteases including blood clotting and the complement activation [34]. Protease inhibition assay involves the inhibition of protease action responsible for the modification of proteins. In this piece of work the synthesized thiourea were also evaluated against protease using in-vitro technique and it was observed that they have moderate potential against protease (Table 3 ).

Table 3. The DPPH and enzyme inhibition activities of the synthesized compounds.

\begin{tabular}{|c|c|c|c|c|c|c|c|c|}
\hline \multirow{2}{*}{ Compounds } & \multicolumn{2}{|c|}{ DPPH } & \multicolumn{2}{c|}{ AChE } & \multicolumn{2}{c|}{ BChE } & Protease & \\
\cline { 2 - 9 } & $\begin{array}{c}\text { \%age } \\
\text { inhibition }\end{array}$ & $\begin{array}{c}\mathrm{IC}_{50} \\
(\mu \mathrm{g})\end{array}$ & $\begin{array}{c}\text { \%age } \\
\text { inhibition }\end{array}$ & $\begin{array}{c}\text { \%age } \\
\text { inhibition }\end{array}$ & $\mathrm{IC}_{50}(\mu \mathrm{g})$ & $\begin{array}{c}\mathrm{IC}_{50} \\
(\mu \mathrm{g})\end{array}$ & $\mathrm{IC}_{50}(\mu \mathrm{g})$ & $\mathrm{IC}_{50}(\mu \mathrm{g})$ \\
\hline $\mathbf{1}$ & $65.1 \pm 1.1$ & $76 \pm 1$ & $54.4 \pm 1.2$ & $189 \pm 3$ & $39.2 \pm 1.0$ & $<200$ & $45.1 \pm 0.8$ & $<200$ \\
\hline $\mathbf{2}$ & $90.5 \pm 2.1$ & $45 \pm 2$ & $74.3 \pm 2.0$ & $119 \pm 2$ & $48.1 \pm 0.7$ & $<200$ & $67.7 \pm 1.4$ & $141 \pm 1$ \\
\hline $\mathbf{3}$ & $87.3 \pm 1.3$ & $49 \pm 2$ & $61.4 \pm 0.5$ & $148 \pm 3$ & $41.4 \pm 0.9$ & $<200$ & $52.9 \pm 0.7$ & $184 \pm 3$ \\
\hline $\mathbf{4}$ & $79.7 \pm 0.7$ & $63 \pm 1$ & $69.7 \pm 0.9$ & $134 \pm 2$ & $45.5 \pm 0.6$ & $<200$ & $58.2 \pm 1.1$ & $173 \pm 2$ \\
\hline $\mathbf{5}$ & $81.6 \pm 0.9$ & $51 \pm 2$ & $55.1 \pm 0.9$ & $181 \pm 4$ & $36.7 \pm 1.1$ & $<200$ & $42.4 \pm 1.0$ & $<200$ \\
\hline STD & $92.7 \pm 0.5^{*}$ & $14 \pm 1$ & $87.2 \pm 0.5^{* *}$ & $27 \pm 1$ & $77.6 \pm 1.0^{* *}$ & $35 \pm 1$ & $90.3 \pm 1.0^{* *}$ & $35 \pm 1$ \\
\hline
\end{tabular}

*Gallic acid; **PMSF.

Docking study of compounds

All synthesized compounds were docked with MOE software by downloading the PDB files of the $\mathrm{AChE}$ and $\mathrm{BChE}$. The docking score and binding energy of each molecule with respect to 
both enzymes is listed in Table 4 and Figures 5 and 6 . The synthesized thiourea (2) depicted most favorable interaction with amino acids loacated $\mathrm{n}$ the active sites of the esterase. The gorge of AChE contains the catalytic triad having Ser203, His447 and Glu334 amino acids, while "peripheral anionic binding site" (PAS), located in the peripheral part of the gorge is composed of Trp84, Tyr334, Trp286 and Tyr72 amino acids. In our study a strong hydrogen bonding was observed with Tyr334 and Tyr70 involving the oxygen atom of the methoxy group of the synthesized molecule. Similarly, nitrogen and oxygen (benzoyl group) of the thiourea derivative showed hydrogen bond with Tyr70, Gly123, Ser81 and Gly117. A $\pi-\pi$ interaction appeared with Tyr334 and Tyr84 in PAS by the benzoid system of the studied thiourea moiety while electrostatic (cation- $\pi$ ) type of interaction was found between ligand and His440 residue (Figure 5). These all interactions indicated the good fit or binding of the crystalline compound to the active site of the AChE. In BChE there is a weak interaction, mainly hydrogen bond interaction with Gly117, Gly116, His438 residues and no $\pi-\pi$ interaction is observed at active site which indicate a weak inhibition (Figure 6). In this study both experimental and theoretical (docking) results are in a close agreement with already reported in the literature [19].

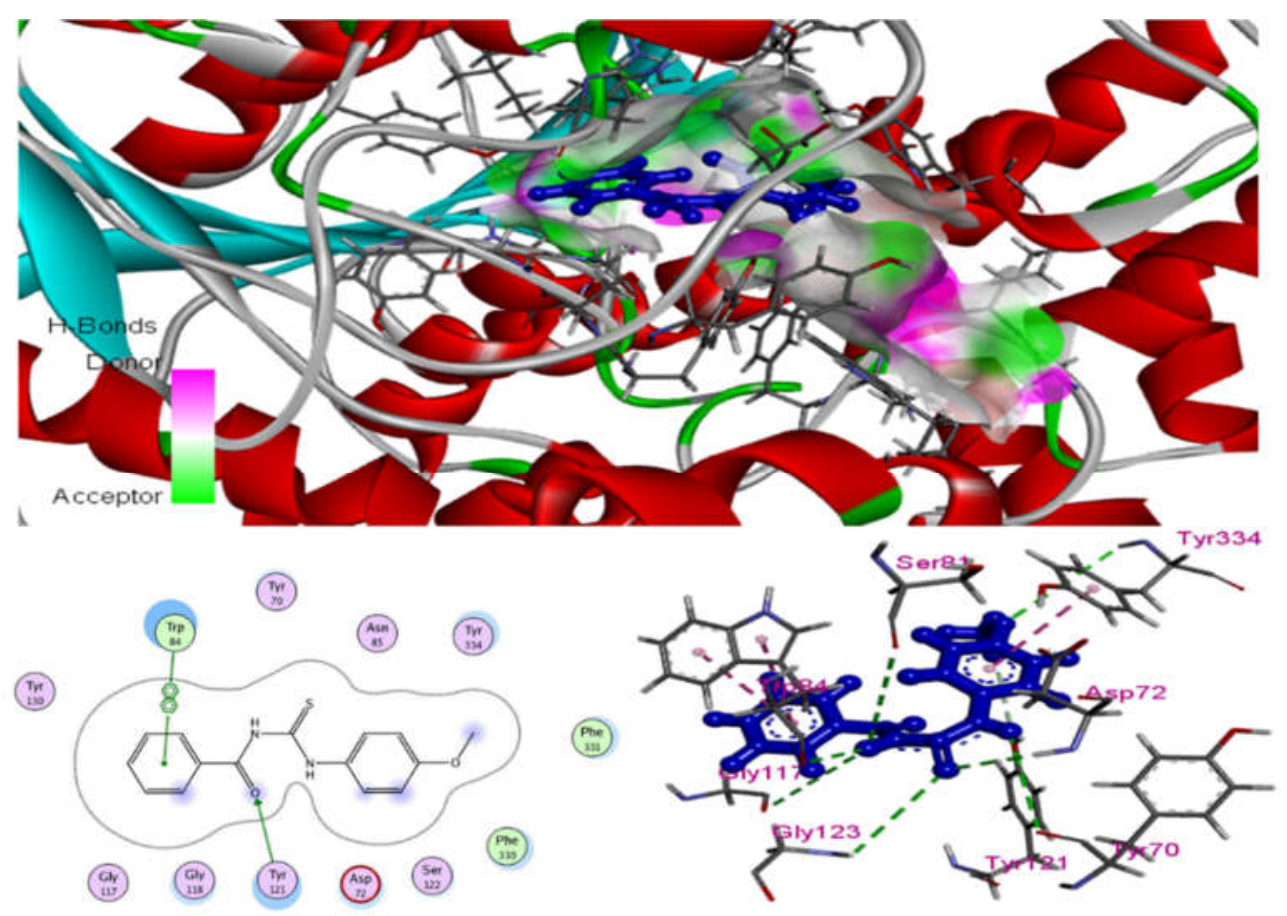

Figure 5. Docked picture of 2 with AChE. 
Table 4. Docking results of the synthesized compound.

\begin{tabular}{|c|c|c|c|c|}
\hline \multirow{2}{*}{ Compounds } & \multicolumn{2}{|c|}{ AChE } & \multicolumn{2}{c|}{ BChE } \\
\cline { 2 - 5 } & Docking score & $\begin{array}{l}\text { Binding affinity } \\
(\mathrm{kcal} / \mathrm{mol})\end{array}$ & Docking score & $\begin{array}{l}\text { Binding affinity } \\
(\mathrm{kcal} / \mathrm{mol})\end{array}$ \\
\hline $\mathbf{1}$ & -5.3591 & -5.5473 & -4.6806 & -5.1256 \\
\hline $\mathbf{2}$ & -6.5958 & -5.7505 & -5.3457 & -4.4313 \\
\hline $\mathbf{3}$ & -5.6653 & -6.3542 & -4.7192 & -4.1733 \\
\hline $\mathbf{4}$ & -6.1841 & -6.1843 & -5.5751 & -5.0333 \\
\hline $\mathbf{5}$ & -5.6095 & -6.3440 & -5.1854 & -4.9845 \\
\hline
\end{tabular}

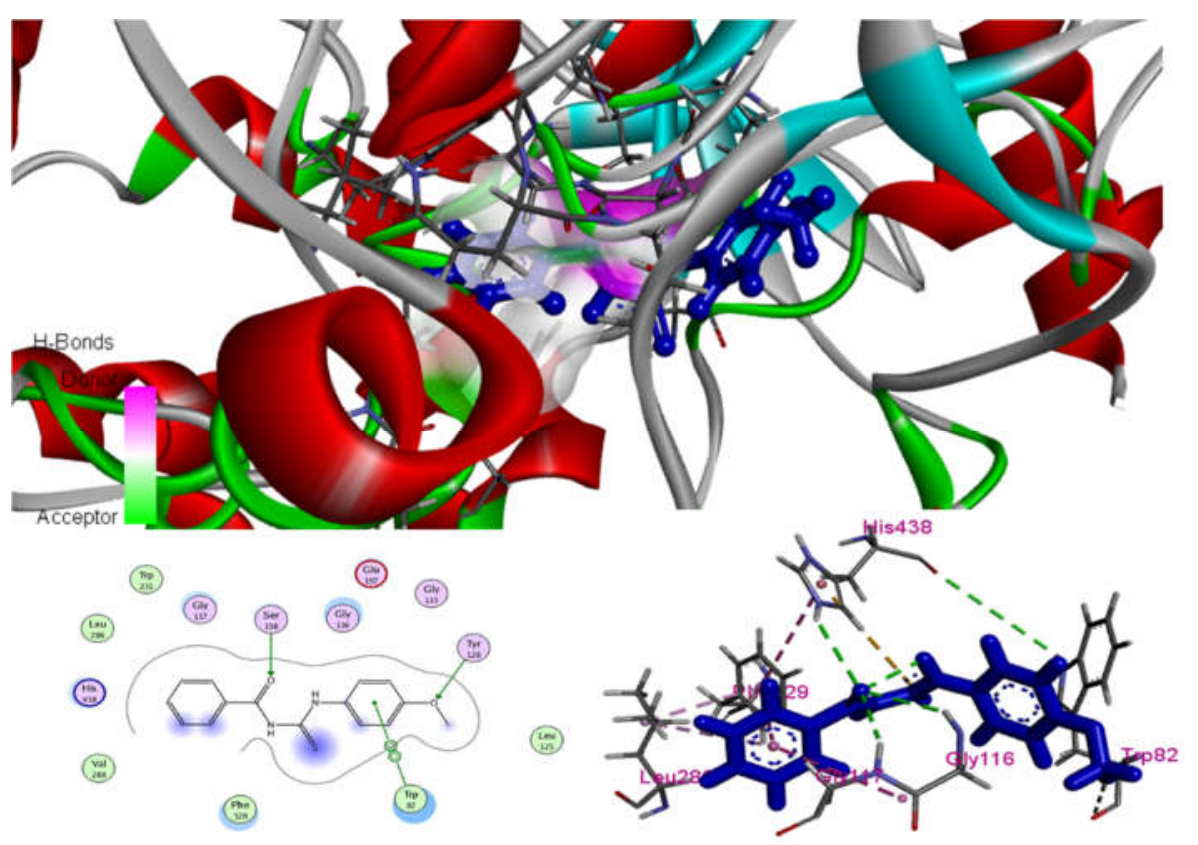

Figure 6. Docked Picture of 2 with BChE.

\section{CONCLUSIONS}

Compounds containing thiourea moiety are emerging in the field of drug discovery due to structural advanced. A number of biological applications can be achieved by an appropriate choice of organic compounds. Current studies concentrated on the synthesis of thiourea derivatives having many pharmaceutical applications included anti-oxidant, anti-bacterial, anti-cancer and enzyme inhibition. In this study substituted amine based thiourea derivatives were synthesized, characterized by theoretical (DFT) and experimental basis. Free radical scavenging and enzyme inhibition potential of studied molecules was depicted using in-vitro models. Docking studies against $\mathrm{AChE}$ and $\mathrm{BChE}$ was carried out which confirmed the practically results (in vitro). Our group is working on designing and synthesizing of molecules having biological potential in the field of medicine for saving human beings. As medicinal applications, synthetic compounds may be the good therapeutic agent against enzymes and free radicals in future. 


\section{REFERENCES}

1. Prabu, S. L.; Suriyaprakash, T. Impurities and its importance in pharmacy. Int. J. Pharm. Sci. Rev. Res. 2010, 3, 66-71.

2. Sheldon, R.A. E factors, green chemistry and catalysis: an odyssey. Chem. Commun. 2008, 3352-3365.

3. Mital, A. Synthetic nitroimidazoles: biological activities and mutagenicity relationships. Sci. Pharm. 2009, 77, 497-520.

4. Nagalakshmi, G. Synthesis, antimicrobial and antiinflammatory activity of 2,5-disubstituted1,3,4-oxadiazoles. Indian J. Pharm. Sci. 2008, 70, 49-55.

5. Nekrasov, D. Biological activity of 5-and 6-membered azaheterocycles and their synthesis from 5-aryl-2,3-dihydrofuran-2,3-diones. Chem. Heterocycl. Compd. 2001, 37, 263-275.

6. Sperry, J.B.; Wright, D.L. Furans, thiophenes and related heterocycles in drug discovery. Curr. Opin. Drug. Discov. Devel. 2005, 8, 723-740

7. Polshettiwar, V.; Varma, R.S. Greener and expeditious synthesis of bioactive heterocycles using microwave irradiation. Pure Appl. Chem. 2008, 80, 777-790.

8. Alkan, C.; Tek, Y.; Kahraman, D. Preparation and characterization of a series of thiourea derivatives as phase change materials for thermal energy storage. Turk. J. Chem. 2011, 35, 769-777.

9. Dua, R.; Shrivastava, S.; Sonwane, S.; Srivastava, S. Pharmacological significance of synthetic heterocycles scaffold: a review. Adv. Biol. Res. 2011, 5, 120-144.

10. Arslan, H.; Duran, N.; Borekci, G.; Koray Ozer, C.; Akbay, C. Antimicrobial activity of some thiourea derivatives and their nickel and copper complexes. Molecules 2009, 14, 519-527.

11. Anbu, P.; Gopinath, S.C.; Cihan, A.C.; Chaulagain, B.P. Microbial enzymes and their applications in industries and medicine. BioMed Res. Int. 2017, 2017, 2195808.

12. Sami, A.J.; Shakoori, A. Cellulase activity inhibition and growth retardation of associated bacterial strains of Aulacophora foviecollis by two glycosylated flavonoids isolated from Mangifera indica leaves. J. Med. Plant Res. 2011, 5, 184-190.

13. Binzet, G.; Kavak, G.; Külcü, N.; Özbey, S.; Flörke, U.; Arslan, H. Synthesis and characterization of novel thiourea derivatives and their nickel and copper complexes. J. Chem. 2013, $1-9$.

14. Shahwar, D.; Raza, M.A. Antioxidant potential of phenolic extracts of Mimusops elengi. Asian Pac. J. Trop. Biomed. 2012, 2, 547-550.

15. Jedinák, A.; Maliar, T.; Grančai, D.; Nagy, M. Inhibition activities of natural products on serine proteases. Phytother. Res. 2006, 20, 214-217.

16. Shahwar, D.; Raza, M.A.; Khan, T. Synthesis and evaluation of enzyme inhibitory potential of some derivatives of scopolamine. Turk. J. Chem. 2012, 36, 257-266.

17. Drissi, M.; Benhalima, N.; Megrouss, Y.; Rachida, R.; Chouaih, A.; Hamzaoui, F. Theoretical and experimental electrostatic potential around the m-nitrophenol molecule. Molecules 2015, 20, 4042-4054.

18. Dege, N.; Raza, M.A.; Doğan, O.E.; Ağar, T.; Mumtaz, M.W. Theoretical and experimental approaches of new Schiff bases: Efficient synthesis, X-ray structures, DFT, molecular modeling and ADMET studies. J. Iran. Chem. Soc. 2021, 18, 2345-2368.

19. Raza, M.A.; Fatima, K.; Saqib, Z.; Maurin, J.K.; Budzianowski, A. Designing of diamino based esterases inhibitors; synthesis, characterization, density functional theory and molecular modeling. J. Mol. Struct. 2019, 712-722.

20. Danish, M.; Bibi, A.; Raza, M.A.; Noreen, N.; Arshad, M.N.; Aisri, M.A. Sulfonamide derived esters: synthesis, characterization, density functional theory and biological evaluation through experimental and theoretical approach. Acta Chim. Slov. 2020, 67, 785-798. 
21. Aisha; Raza, M.A.; Sumrra, S.H.; Javed, K.; Saqib, Z.; Maurin, J.K.; Budzianowski, A. Synthesis, characterization and molecular modeling of amino derived thiazolidinones as esterase and glucosidase inhibitors. J. Mol. Struct. 2020, 1219, 128609.

22. Silveira, R.G.; Catão, A.J.; Cunha, B.N.; Almeida, F.; Correa, R.S.; Diniz, L.F.; Tenório, J. C.; Ellena, J.; Kuznetsov, A.E.; Batista, A.A. Facile synthesis and characterization of symmetric N-[(phenylcarbonyl) carbamothioyl] benzamide thiourea: Experimental and theoretical investigations. J. Braz. Chem. Soc. 2018, 29, 2502-2513.

23. Sheldrick, G.M. SHELXT-Integrated space-group and crystal-structure determination. Acta Crystallogr. A 2015, 71, 3-8.

24. Jensen, F. Introduction to Computational Chemistry, John Wiley \& Sons: New York; 2017.

25. Tang, C.L. Fundamentals of Quantum Mechanics: For Solid State Electronics and Optics, Cambridge University Press: U.K.; 2005.

26. Sumrra, S.H.; Kausar, S.; Raza, M.A.; Zubair, M.; Zafar, M.N.; Nadeem, M.A.; Mughal, E. U.; Chohan, Z.H.; Mushtaq, F.; Rashid, U. Metal based triazole compounds: Their synthesis, computational, antioxidant, enzyme inhibition and antimicrobial properties. J. Mol. Struct. 2018, 1168, 202-211.

27. Shakeel, A.; Altaf, A.A.; Qureshi, A.M.; Badshah, A. Thiourea derivatives in drug design and medicinal chemistry: A short review. J. Drug Des. Med. Chem. 2016, 2, 10-20.

28. Yapati, H.; Devineni, S.R.; Chirumamilla, S.; Kalluru, S. Synthesis, characterization and studies on antioxidant and molecular docking of metal complexes of 1-(benzo[d]thiazol-2-yl) thiourea. J. Chem. Sci. 2016, 128, 43-51.

29. Tahir, S.; Badshah, A.; Hussain, R.A.; Tahir, M.N.; Tabassum, S.; Patujo, J.A.; Rauf, M.K. DNA-binding studies and biological activities of new nitrosubstituted acyl thioureas. J. Mol. Struct. 2015, 1099, 215-225.

30. Ejidike, I.; Ajibade, P. Synthesis, characterization and biological studies of metal(II) complexes of (3E)-3-[(2-\{(E)-[1-(2, 4-dihydroxyphenyl) ethylidene] amino $\}$ ethyl) imino]-1phenylbutan-1-one Schiff base. Molecules 2015, 20, 9788-9802.

31. Munoz-Muriedas, J.; Lopez, J.; Orozco, M.; Luque, F.J. Molecular modelling approaches to the design of acetylcholinesterase inhibitors: new challenges for the treatment of Alzheimer's disease. Curr. Pharm. Des. 2004, 10, 3131-3140.

32. Xu, Y.; Colletier, J.P.; Jiang, H.; Silman, I.; Sussman, J.L.; Weik, M. Induced-fit or preexisting equilibrium dynamics? Lessons from protein crystallography and MD simulations on acetylcholinesterase and implications for structure-based drug design. Protein Sci. 2008, 17, 601-605.

33. Elumalai, K.; Ali, M.A.; Elumalai, M.; Eluri, K.; Srinivasan, S. Acetylcholinesterase enzyme inhibitor activity of some novel pyrazinamide condensed 1,2,3,4-tetrahydropyrimidines. Biotechnol. Rep. 2015, 5, 1-6.

34. García-Carreño, F. Protease inhibition in theory and practice. Biotechnol. Edu. 1992, 3, 145150. 